\title{
"On Facebook I met old friends again": The use of ICTs in the process of reminiscence among older adults
}

\author{
Marije Blok MSc ${ }^{a, b, c, *}$, Almar A.L. Kok PhD ${ }^{d, e}$, Alice H. de Boer PhD ${ }^{a, f}$ \\ ${ }^{a} \mathrm{VU}$ Amsterdam, Department of Sociology, The Netherlands; ${ }^{b}$ National Foundation \\ for the Elderly, Amersfoort, The Netherlands; 'Leyden Academy on Vitality and Ageing, \\ Leiden, The Netherlands; ${ }^{d}$ Amsterdam UMC, Vrije Universiteit Amsterdam, Epidemiol- \\ ogy \& Data Science, Amsterdam Public Health Institute, Amsterdam, The Netherlands; \\ eAmsterdam UMC, Vrije Universiteit Amsterdam, Psychiatry, Amsterdam Public Health \\ Institute, Amsterdam, The Netherlands; ${ }^{f}$ Netherlands Institute for Social Research (SCP), \\ The Netherlands; *Corresponding author: m.blok@vu.nl
}

\begin{abstract}
Background: Reminiscence can be beneficial for social and emotional wellbeing at older ages, yet little is known about what this process looks like as well as about Information and Communication Technologies' (ICTs) potentials. Broader understanding would allow us to better tailor interventions and make them more effective using ICTs.

Objective: This qualitative study aims to gain insight into the process of recalling memories in daily life among independent older adults, with special attention to the role of ICTs. Method: We used a two-step approach, starting with explorative interviews with older adults $(\mathrm{N}=20)$, aged 75 to 95 , about their experiences with recalling memories. After this, participants used a diary to track examples of memories over three weeks. We returned to elaborate on the cases described by the participants.

Results: Four stages were derived from the data, including the start of a memory; motivations for pursuing or ignoring a memory; engagement with the memory; and next steps. We found that ICTs are used mainly at the beginning of the process as well as in the stage of engaging with the memory.

Conclusion: ICTs can facilitate sensory triggers, unlock information to complete a memory, and facilitate the company of others - either triggering or sharing memories. Whereas existing interventions mainly focus on initiating memories, often with old triggers, our findings suggest that recalling memories can play a valuable role in connecting older adults with others across age groups. ICTs can facilitate this interaction in several ways.
\end{abstract}

Keywords: Memories, technology, media, qualitative research methods

\section{INTRODUCTION}

A phenomenon closely related to the process of ageing is looking back on life, or, in other words, reminiscence (Butler, 1963). In its broadest sense, reminiscence can be defined as "the vocal or silent recall of events in a person's life, either alone or with others" (Woods et al., 1992). Although reminiscence is increasingly considered as something people at all ages do (Parker, 1995), several studies showed benefits, particularly among older adults. Earlier literature reported positive effects of recalling memories on perceived levels of social and emotional wellbeing such as identity-forming, enhancing meaning in life, preserving a sense of mastery, and promoting acceptance and reconciliation (Bohlmeijer et al., 2007). Other research showed that older adults recall their past more positively than they reported at the time (Ready et al., 2007). This age-related shift from negative to positive memories is called the positivity ef- fect (Mather \& Carstensen, 2005) and is known to compensate for a decline in quality of life. As reminiscence is associated with positive effects in later life, its principles have been integrated into multiple interventions for specific groups of older people, such as those with cognitive impairments, psychosocial decline, or depression (e.g., Gibson, 2004; Alqam, 2018). Less is known, however, about the process of recalling memories among independent older adults in daily life. A better understanding of this process is relevant as this allows us to better tailor interventions and provide the right conditions for older adults to recall memories in a way that contributes to their wellbeing.

Earlier studies described the value of Information and Communication Technologies (ICTs) in strategies for maintaining social and emotional wellbeing at older ages (e.g., Blok et al., 2020), thus we may expect ICTs to play a role in remi- 
Table 1. The MAIN model.

\begin{tabular}{|c|c|c|}
\hline Affordance & Definition & Gratifications \\
\hline Modality & $\begin{array}{l}\text { Refers to the different methods of } \\
\text { presentation of media content, } \\
\text { appealing to different aspects of the } \\
\text { human perceptual system. }\end{array}$ & $\begin{array}{l}\text { Realism } \\
\text { Coolness } \\
\text { Novelty } \\
\text { Being there } \\
\end{array}$ \\
\hline Agency & $\begin{array}{l}\text { Allows users to be agents or sources } \\
\text { of content on the internet. }\end{array}$ & $\begin{array}{c}\text { Agency-enhancement } \\
\text { Community-building } \\
\text { Bandwagon } \\
\text { Filtering/tailoring } \\
\text { Ownness }\end{array}$ \\
\hline Interactivity & $\begin{array}{l}\text { Allows users to interact with and } \\
\text { through the medium. }\end{array}$ & $\begin{array}{l}\text { Interaction } \\
\text { Activity } \\
\text { Responsiveness } \\
\text { Dynamic control }\end{array}$ \\
\hline Navigability & $\begin{array}{l}\text { Allows users to easily move through } \\
\text { the medium. }\end{array}$ & $\begin{array}{c}\text { Browsing/Variety seeking } \\
\text { Scaffolds/Navigation aids } \\
\text { Play/Fun }\end{array}$ \\
\hline
\end{tabular}

niscence too. Several studies elaborated on the potentials of using ICTs in reminiscence-based interventions (e.g. Brankaert et al., 2016; Lazar et al., 2014; Sun et al., 2020;). The opportunities of social networking sites for triggering memories have also been described (e.g., Thomas \& Briggs, 2016). Whereas previous studies investigated tools proactively prompting users, for example with (old) pictures, less is known about the use of ICTs in everyday reminiscence.

\section{Aim and research questions}

This study aims to explore the extent to which ICTs can facilitate the process of recalling memories among older adults, elaborating on two research questions:

1. What does the process of recalling memories among older adults look like?

2. What role do ICTs play throughout this process?

Understanding the role of ICTs in the process of reminiscence is relevant as it allows more effective support of older adults in recalling memories and thus contributes to successful ageing.

\section{Dimensions of reminiscence}

Although little is currently known about the everyday processes of reminiscence among older adults, the literature provides starting points for studying it. In his Reminiscence Function Scale, Webster (1992) described the eight main functions of reminiscence, including boredom reduction; death preparation; identity; problem-solving; conversation; intimacy maintenance; bitterness revival; teach/inform. Thornton and Brotchie (1987) elaborated on dimensions observed in reminiscence. First, they distinguished between purposive and spontaneous reminiscence; and, second, between silent (or individual) and oral (or conversational) recalling of memories. In terms of content, they differentiated memories of approximately five years ago from those of the remote past. We consider these dimensions useful starting points in further exploring the process of reminiscence among older adults.
Theory on the use of ICTs

We explored the use of ICTs through an affordances lens, focusing on the possibilities that emerge when actors engage with technology (Faraj \& Azad, 2013). In the MAIN model, Sundar and Limperos (2013; Table 1) describe the mostobserved affordances of new media, including modality, agency, interactivity, and navigability. Additionally, they describe gratifications derived from these affordances: fulfilled needs acquired either deliberately or by chance. New media are considered as novel communication technologies, ranging from the variety of devices (smartphones, PCs) to channels (internet, cable) and venues on those channels (social networking sites, smartphone apps) affording users the ability to interact with these media but also through them with other users.

To explore the process of reminiscence among older adults, we conducted a qualitative interview study using the dimensions found by Thornton and Brotchie (1987) as sensitizing concepts. Inspired by the MAIN framework, we investigate the role of ICTs throughout this process.

\section{Methods \\ Recruitment and selection of participants}

We conducted a qualitative interview study in the Netherlands. Participants were recruited through convenience sampling among the network of the National Foundation for the Elderly, a charity combatting loneliness among vulnerable older adults. First, we sent an invitation e-mail to older adults matching the inclusion criteria (aged 75+, living independently; $\mathrm{N}=54$ ). Eight of them responded positively; six did not wish to participate. The main motivations for not participating included not being available (due to hospitalization or holiday) or a negative attitude towards recalling memories. The latter was expressed in two ways: some did not want to talk about the past because of bad memories; others were defensive because they considered reminiscence something for 'old' people, not themselves. Those who did not respond at all were called by telephone, five of whom were willing to participate. We also published an announcement in the newsletter of a co-living complex; this yielded seven more participants. Eventually, the study included 20 participants, six men, and fourteen women, aged 75 to 95 (average 82.3).

\section{Data collection}

We visited participants twice for a semi-structured qualitative interview (see supplementary material) and gave them a diary (see supplementary mate- 
rial) to track their memories between our visits. Interviews took place in the spring of 2019; all were conducted by Marije Blok (the corresponding author of this manuscript), assuring a similar approach to each participant thus increasing internal validity. All interviews took place in a one-to-one situation at the participant's home. The first interviews took approximately 20 minutes; the second interviews lasted about 45 minutes. The first interview started with a series of background questions, such as age, marital status, family, and living situation. We introduced the concept of recalling memories by asking some questions about recent memories aimed at making them aware of how they recollect memories. If they found it difficult to give examples, we supported them by mentioning functions of reminiscence described by Webster (1993). Additionally, we asked participants about their attitude towards and experiences with ICTs to make them sensitive to this topic as well. For the three weeks between the interviews, participants used the diary to record situations in which they recalled memories. We supported them by providing some questions derived from the dimensions described above (Thornton \& Brotchie, 1987), such as how the memory started; whether the memory was recalled alone or with others; who took the initiative; and whether the memory was about a short time ago or a different phase in life. In the second interview, we asked elaborative questions on the examples that participants had written. If not explicitly mentioned yet, we asked about the use of ICTs in the examples as well. We explained the concept of ICTs in line with the concept of new media (Sundar \& Limperos, 2013).

The use of open, qualitative methods allowed a rich exploration of participants' experiences and helped to gain an in-depth understanding of the processes among this group. The interactive character of the data collection enhanced the internal validity, enabling us as researchers to probe and ask for clarification. Conducting interviews face-to-face advanced our understanding of the situation, which was beneficial for our interpretation of the data.

\section{Ethical considerations}

Before the data collection, an online ethical self-check provided by the faculty ethics committee was performed. The self-check indicated no need for obtaining official approval as we included adult participants able to decide for themselves about what to share or not. Informed consent was acquired by all participants and the interviews were processed anonymously and stored separately from any personal details. As we emphatically did not want to force participants to share information that made them feel uncomfortable, we did not ask them to give us the diary afterward. Nevertheless, some of them did. We marked each of these diaries with an anonymous code and referred to it when the transcriptions missed details.

\section{Data analysis}

We analysed our data in an iterative process, optimizing the interpretation of data. All interviews were audio-recorded, with each participant's permission, and transcribed verbatim. First, Marije Blok coded them using Excel, focusing on information providing insight into what happened during the process. Next, a colleague who did not participate in this study separately coded the data of three random participants. Both coders compared which data they highlighted as being relevant and the codes assigned to them. No serious differences in interpretation were noticed when comparing the two. In an initial round of iteration, we clustered codes around several broader topics including conditions under which reminiscence started; characteristics of the process; the use of ICTs; and the content of memories. In the subsequent step of analysing the data, we focused on the sequence of events and transitions in the process. Based on this analysis, we decided to divide the results into different stages. Particularly helpful for distinguishing these stages were situations in which some of the participants quitted the process - either consciously or unconsciously - whereas others continued. We considered these moments as indications of transitions between stages. Initially, we defined three stages but throughout the iterative and interactive process of labeling, we decided to split the stages of motivations and engagement - that we first considered one stage - into two separate stages.

Finally, we agreed that the data contained sufficient richness and clarity to formulate themes and subthemes per stage. In this final stage, we also reflected on the use of ICTs throughout the process, inspired by the MAIN framework.

\section{Results}

Inductively analysing the data we discovered that dividing the recalling process into four sequential stages provided an appropriate way to present our findings. We labelled the stages: how a memory starts; motivations to pursue or ignore the memory; engagement with the memory, and next steps. An overview of the stages and corresponding themes can be found in Table 2 .

\section{How a memory starts}

Elaborating on their memories, participants distinguished five types of starting points. We labeled these: sensory triggers; meaningful moments; locations; objects; and the company of others.

The process of recalling a memory was often started with a sensory trigger. Participants re- 
Table 2. Stages of reminiscence.

\begin{tabular}{|c|c|c|c|c|}
\hline Stage & How a memory starts & $\begin{array}{c}\text { Motivations to pursue or } \\
\text { ignore the memory }\end{array}$ & $\begin{array}{c}\text { Engagement with the } \\
\text { memory }\end{array}$ & Next steps \\
\hline \multirow[t]{2}{*}{ Characteristics } & \multirow{2}{*}{$\begin{array}{l}\text { - Sensory triggers } \\
\text { - Meaningful moments } \\
\text { - Locations } \\
\text { - Objects } \\
\text { - Company of others }\end{array}$} & $\begin{array}{l}\text { - Homesickness } \\
\text { - Curiosity } \\
\text { - Connectedness with } \\
\text { others }\end{array}$ & $\begin{array}{l}\text { - Reconstructing } \\
\text { - Relating } \\
\text { - Reviving }\end{array}$ & $\begin{array}{l}\text { - Triggering emotions } \\
\text { - Involving others } \\
\text { - Reflection }\end{array}$ \\
\hline & & $\begin{array}{l}\text { - Resistance to being old } \\
\text { - Anticipating negative } \\
\text { emotions }\end{array}$ & & \\
\hline $\begin{array}{l}\text { The role } \\
\text { of ICTs }\end{array}$ & $\begin{array}{l}\text { - Facilitating sensory } \\
\text { triggers } \\
\text { - Facilitating the company } \\
\text { of others }\end{array}$ & & $\begin{array}{l}\text { - Unlocking information } \\
\text { to enrich the memory } \\
\text { - Facilitating company } \\
\text { with others }\end{array}$ & \\
\hline
\end{tabular}

ferred here to visuals as the most powerful. This, on the one hand, included old images, displaying the past in general or someone's personal history in particular; on the other hand, contemporary images reminded participants of previous situations. Examples of analogue images included printed photographs, either from a personal collection or in print media such as newspapers or books. For some participants, the mere thought of a photograph in their collection was enough to trigger a memory. One man elaborated in detail on the trips he had made for his former job in the Navy, based on a particular picture he had in mind. Others indicated the presence of pictures as an important condition for recalling memories; a participant who lost her photographs after her divorce, illustrates well how pictures were considered as actual memories:

"I do have some pictures, but not that many. When I got divorced, they all stayed with him. When he died, I wanted them. But it was all confiscated, because of his debts. All my photos, all those memories are gone. I was very sorry about that." (D21)

In addition to printed photographs, participants mentioned how they viewed digital images on personal devices such as smartphones, tablets, or computers. Social media, such as Facebook pages of a historical neighbourhood, were also mentioned as sources for finding and seeing (old) images that recalled the past. Furthermore, participants described how they used their laptop or tablet to make memory books of vacations or mark an anniversary. Some participants indicated that digital pictures were easier to organize and look through compared to an archive of printed pictures. Others did not perceive digitized pictures as positive, because they considered digital photo collections as less tangible.

Participants mentioned audio-visual media such as VHS or DVD as triggering personal memories. The television was also cited as an important device. Often, contemporary rather general (news) items triggered personal memories. One participant shared how a news report of the fire at the Nôtre Dame Cathedral reminded her of a vaca- tion in Paris years ago. Someone else told us how football matches on television triggered memories of her son, a professional soccer player who died in a car crash forty years ago.

Another type of sensory trigger was sound. These triggers included random sounds such as the noise at a swimming pool as well as music, for instance, a barrel organ melody at a marketplace. ICTs - radio, CD, and LP players - were often used to listen to music. The interviews were conducted around Easter, thus Bach's Matthew Passion listened to on CD, was mentioned several times as recalling (family) traditions from the past. Other pieces of music also recalled personal memories:

"I saved all my LPS! When I play an LP with a pianist I had heard in 1974 in Bregenz, I have to think about it. What he played, what the atmosphere was like. That we were in such a concert hall and suddenly a terrible thunderstorm erupted." (D9)

Meaningful moments were also considered important starting points for a memory, most notably significant dates in a participant's life and occasions such as birthdays, the date a beloved one passed away, or wedding anniversaries. One man, for example, shared how he thought of his deceased father on the date that had been his birthday. Additionally, participants elaborated on dates with broader relevance. We conducted the interviews during spring and for many Dutch older adults May 4 (Memorial Day) and May 5 (Liberation Day) were important occasions for reflecting on their experiences during the second world war. Other holidays, such as Good Friday, Easter, or King's Day reminded participants of how they had given substance to these moments in the past:

"On King's Day, I always think of my [deceased] mother. Because in the past on this day we always went to my mother's. I got tompouces at the HEMA in the morning, my husband got bitter orange, and then we all watched TV." (D18)

Other types of meaningful moments included life events, often in the lives of younger-genera- 
tion relatives. These moments made participants look back on the days they joined in these life events themselves. One woman described how preparations for her granddaughter's wedding had reminded her of the preparations of her own wedding sixty years earlier, and how she had made her wedding dress.

Some memories started with locations. Places like houses, holiday destinations, neighbourhoods, or even countries someone had lived for a certain period, reminded participants of either what had happened at a place in the past or to a broader timespan related to this location:

"When I'm sitting in the sun, drinking coffee and I look at that house, I think: 'If you had seen what it was like when we bought it. Really a ruin.' Those memories of the renovation also come to the fore when I see what it looks like now." (D4)

Additionally, participants described examples in which objects initiated the process of reminiscence. These included old objects, recalling memories of their own lives back in the days, but also objects of deceased beloved ones that reminded them of those persons. Sometimes objects such as souvenirs were specifically purchased to remember moments, whereas in other cases these had become memories over time. One woman told us about her deceased husband's guitar; when he passed away, she initially thought that she did not need this guitar anymore, but once her son had taken it, she realized this object had emotional value for her and she had tearfully asked for it back.

A final type of starting point mentioned was the company of other persons, either one-to-one or in a group. Several participants indicated that sometimes just the company of (close) others was sufficient to start a conversation about the past. In addition to instances in which memories were triggered by being together in real life, participants described examples of the company of others without physical presence, mediated by ICTs. The telephone was most often used to spend time together. One participant told us about his daughter and granddaughter living in the United States. During a recent phone call, he had experienced the closeness of their company and the memories of their vacation together came up automatically, despite the physical distance. Participants also mentioned digital platforms such as Facebook as a virtual way to meet old acquaintances or relatives. These persons, who would otherwise have disappeared out of their lives, reminded our participants of the past by just being present, even online:

"On Facebook, I met old friends and family members again I otherwise would never speak to again. I hadn't had any contact with them for years, but now I do again." (D7)

\section{Motivations to pursue or ignore memories}

Once a process of reminiscence was initiated, if and how this was continued depended mainly on participants' motivations. Aside from participants indicating their openness to recalling memories - nothing more or less - we found five types of motivations: Whereas homesickness, curiosity, and connectedness with close others motivated older adults to pursue a memory, resistance to being old and the anticipation to experience negative emotions obstructed the process after a memory had started.

Some participants described how, homesickness motivated them to recall memories and (pro-)actively engage in reminiscence. These participants preserved old objects and considerable collections of old photographs. Homesickness was described by participants as a nostalgic longing back for the past, triggering positive emotions as they remembered the past as a pleasant, often carefree, era:

"I feel a bit homesick for the old days [smiles]. Then I think: 'What a great time it was with those little children'." (D11)

The second was reminiscence driven by curiosity - characterized as a rather sober and cognitive effort aiming to complete memory with the right details. One participant shared with us that visiting a city triggered a memory and that she was frustrated about no longer being able to recall the exact details. A third motivation for continuing the process was connectedness with others. Some participants organized social events to talk about the past and spend time together in an enjoyable way. In other cases, this connectedness was closely related to emotional support:

"I call her [sister] every day. If she is very sad, I try to remember something. About my father, for example. Then I say: 'Do you remember that?' Then she says: 'Of course,' and she starts too and is out of her grief for a while. I do that very consciously." (D17)

In contrast to motivations for continuing the process of remembering, participants mentioned motivations for ignoring or aborting the process.

A fourth motivation can be described as a resistance to being old. The perception that recalling memories is something "only silly or forgetful people do", obstructed the process in several cases. One woman 'confessed' that she sometimes caught herself talking to a picture of her deceased husband, embarrassing herself with this 'elderly behaviour' that she tries to avoid.

A fifth motivation, that also prevented participants from further engagement, was the anticipation of experiencing negative emotions. Most 
often this was about triggering recollections of negative events from the past that participants did not want to stir up. In other cases, the occurrences were positive, but recalling these events confronted participants with the fact those good times were over. Sometimes participants obstructed the process after a negative memory was recalled, whereas in other cases, they avoided triggering them at all. For some older adults, this reluctance was even a reason to not participate in our study at all:

"No, I don't like to hear anything about the war [tears in my eyes], as all those horrible visions then resurface again. I don't read books about the war, nor articles. Even now you get those commemorations again. I don't want any of that. As soon as I see something of the war, I don't look at it at all". (D2)

\section{Engagement with the memory}

When participants were motivated to pursue a memory, we found three ways in which they engaged with it, including reconstructing the past; relating the present to the past; and actively reviving the past.

First, participants described situations in which they reconstructed experiences from the past. This process was rarely solitary but usually involved different conversation partners, all of them adding new elements to the story. Involved people spontaneously shared associations, asking each other questions and together completing the memories. Reconstructed stories were often from the remote past; participants discussed topics such as perceptions of their upbringing, vacations, family traditions, or deceased persons. Sometimes all conversation partners equally contributed to such a reconstruction, whereas in other examples, some group members knew more than others. One woman told us that her mother had passed away when she was fifteen and that as the oldest of ten children, she was the only one with clear memories of that time, so her younger siblings often asked her to reconstruct the experiences for them. Discovering and comparing memories helped participants feel connected to others, even if they did not know them very well. One participant shared that the sons of her ex-husband contacted her to ask questions about their father who had recently passed away. Together they completed the story and learned from each other. Another participant described how he had discovered common relatives with a woman at his walking club who had been married to his cousin:

"Her ex-husband was a cousin of mine, with whom I spent a lot of time in high school. So we put together things that she knew about him and that I remembered about him. Separately we had been through the same thing. We ex- changed that and started to put memories next to each other, as it were." (D14)

ICTs were useful in this process in two ways. First, ICTs could help participants seek more information about a particular memory. Participants viewed their devices as useful because they could easily find additional information and missing details. One participant indicated that since digitizing his photo archive, he found it much easier to find the right pictures. This man now attached digital pictures to his emails, supporting a memory shared with the recipient. The digital picture enriched this experience in a way printed pictures would not have allowed. Second, ICTs were helpful in this stage in reconstructing the past without others being around. One woman told us that she regularly called her sister to reconstruct their time in Indonesia, where they had lived when they were little girls. Someone else had called his brother to recall memories of their deceased father. He explained how he nowadays has more contact with his brother than when they were young, as recalling memories connected them and the use of technology allowed them to do so.

A second way of engaging with the memory included the process of relating and comparing occurrences in the present to the past and vice versa. Interaction between generations was typical for this process. Several participants explicitly described how they loved conversations with younger people as these reminded them of the past and at the same time helped them stay involved in the present. One participant told us about a WhatsApp conversation with her granddaughter about the break-up with her boyfriend. As this reminded the participants of her divorce decades ago, the conversation, in the end, was about experiences of both present and past. Someone else elaborated on a chat with a younger person about his work as a dentist and his thoughts about quitting his job. This conversation reminded the participant of when he was still working so he responded with his own experiences from the past. Older adults often engaged in this type of process to help younger generations learn about the past. One participant told us how she taught her grandchildren about old table etiquette; another elaborated on how she shared her experiences raising children with her grandson who had recently become a father. Another example is that of a participant who shared experiences of her own first communion with her granddaughter after attending her ceremony. Having saved a picture of her own event on her tablet, she could easily support her story:

"The memory of my communion dress was the topic of conversation. I have one picture of myself from back then. And then you see what you 
looked like. My granddaughter liked that. Because I also showed that picture. I found it on my device, I could summon it." (D4)

Aside from participants proactively teaching younger conversation partners, younger persons also asked questions about the past themselves. Our participants were often happily surprised as they did not expect them to be interested in the past. One participant indicated that her granddaughter regularly asked her about school in her childhood. Another participant told us that her granddaughter invited her to go with her to see a popular Dutch play about the second world war as she wanted to learn more about this period. In these conversations both present and past were important, and both generations engaged and asked each other questions, thus keeping the conversations alive.

As in this type of engaging with the memory conversation with others, often younger ones, played an important role, ICTs were mainly used to mediate this contact.

Eventually, participants elaborated on activities employed to revive the past. First were examples in which participants conducted activities like as they had in the past themselves. One participant shared with us that she visited the botanical garden while remembering how she had strolled among the rocks with her now-deceased husband. Several participants shared their habits of kissing their deceased husband's pillow goodnight, still perceiving their presence in the bedroom. Second, participants described how they relived the activities of a deceased loved one to keep their memory alive and stay connected. One participant told us how she loved gardening while wearing the gloves of her deceased husband. Someone else described a trip she had made, following directions she had been by her father-in-law back:

"My father-in-law was arrested during a raid to come and work in Germany. And with that terrible winter of hunger, he came back, with horse and cart, from the area of Munich. He described that trip in a booklet, which I later made in reverse with my husband and children. That was very special." (D9)

A final way of reviving the past included rather symbolic activities aimed at purposefully remembering. Participants described activities that help them feel emotionally connected to the past or someone no longer living. Examples on a personal level included bringing flowers to a grave; watching holiday pictures; or painting a portrait of a deceased husband. Examples of remembering on a more general level included mainly war memorials. One participant mentioned his attend- ance at a ceremony in his hometown to remember the bombings in the second world war. At the annual memorial he very consciously memorialized the occurrences, in which he lost his father:

"Something terrible happened in my youth. We lived in Nijmegen and bombs fell there and my father died as a result. Every year we have a commemoration of that bombardment. And that's something you do very consciously. That's really the organized evoking of memories, that doesn't happen spontaneously." (D14)

In reviving the past ICTs did not play a crucial role, as there was more emphasis on (physical) activities. Nevertheless, some participants described how they watched memorials at TV.

\section{NeXt STEPS}

The stage of engaging with the memory was not always the end of the process. Participants described several ways in which recalling memories led to new processes, including emotions triggering new processes, involving others, and reflection.

First, in several cases, the process of recalling memories triggered emotions - either positive or negative. Sometimes this triggered further continuation of the process, for example, by raising new questions to be answered:

"Those 'play' (of soldier of orange) were emotional memories. Many people were emotional. I also had to cry a little bit. Because of that she [granddaughter] came up with all kinds of questions, also emotional questions." (D16)

Second, the individual recalling of memories sometimes triggered participants' need to involve others. Whereas in some instances participants felt like sharing their experiences themselves, in others, they were responding to questions. One participant told us that he had invited his children to join him at an annual memorial which he used to attend alone. Being there prompted questions from his children that led the participant to recall and talk about more memories related to the war: "Because it... I do not want to call it an anniversary, but it is 75 years ago, I asked my children to join me. And of course they wanted to know more - because I've never told them so much about what it's done to me. And then you start talking about those things to each other." (D14)

Third, several participants described how recalling memories triggered processes of self-reflection. One participant was preoccupied with the question of why she was so frequently triggered to think of one of her three former husbands in particular, whereas memories of her other spouses were rare. Another participant shared how recalling memories allowed her to reflect on how the past had shaped her into the person 
she currently was:

"Later I thought, as I got to know my husband, I was just looking for a second father, I missed him so much. The same type, very caring. I was never aware of that, but now I am. Now I look at it differently. If you're in the middle of it, you don't see it." (D7)

\section{Conclusion}

Based on qualitative interviews and memory diaries, we gained a detailed picture of how older adults recall memories in daily life and of the role of ICTs throughout this process. For understanding the process of reminiscence, we found that it is helpful to distinguish four stages, including the start of a memory; personal motivations to pursue or ignore a memory; engagement with the memory; and next steps. Regarding the role of ICTs throughout this process, we found these to be of added value particularly at the start and in the stage of engagement with the memory. Participants considered ICTs especially useful to trigger sensory perceptions to connect with others who triggered memories, and to share memories with them. Understanding this process as well as understanding the potential of ICTs allows us to better support older adults in recalling memories and improve reminiscence-based interventions aimed at enhancing the wellbeing of older adults.

\section{The process of reminiscence}

Elaborating on what happens throughout the process, our findings enrich the existing literature that primarily focuses on the outcomes and functions of reminiscence (Bohlmeijer et al., 2007; Webster, 1993). Teaching and informing younger generations, for example, was described in the literature as an important function of reminiscence. Whereas previous studies emphasized the older adult as the teacher, we provide insight into the process and found both generations to be equivalent conversation partners, both learning from each other. Another example includes conversation. Whereas Webster introduced conversation as an important function of reminiscence, our data give substance to this concept by elaborating on the context in which this conversation takes place. For instance, we found that older adults can experience connections with both others with a shared background as well as others with a different background.

The distinction of stages allows us to better understand under what conditions recalling memories is successful and contributes to feelings of wellbeing. In some cases, the process of reminiscence was already obstructed before it was even initiated, for example, because the older adult was afraid this would trigger negative memories. In other cases, the process was aborted later on due to a lack of motivation to continue the pro- cess. Understanding the different steps as well as the transition from one stage to another - the moments participants sometimes experienced obstructions - is useful to better support the process.

\section{The role of ICTs}

ICTs were especially of added value at the start and in the stage of engaging with the memory. At the start, ICTs played a role in facilitating sensory triggers as well as the company of others. ICTs first were used to view digital pictures or audiovisual footage or to listen to music that triggered memories. In terms of the MAIN model, we can consider the use of ICTs in this context for the gratification of realism or being there as it allowed older adults to feel close to the moment represented. Additionally, ICTs provided opportunities to find others that remind them of earlier stages in their lives. In terms of the MAIN model, we can explain the use of ICTs to facilitate the company of others as the affordance of modality and the gratification of being there. The use of online platforms such as Facebook to find others can be explained by the affordance of agency, with the gratification of community-building.

In the engagement with the memory, participants used ICTs to unlock information to enrich a memory and to connect with others to recall memories together. In terms of the MAIN model, the perception of being there was an important gratification of using ICTs to search for digital pictures as these allowed older adults to feel close to the past. In unlocking additional information, the opportunities for navigability were an important affordance as well. Whereas many participants indicated that they never looked at albums of printed photographs in their attic, ICTs provided several opportunities to easily find the information sought. When it comes to recalling memories together, ICTs were used for the gratification of interaction.

Contrary to earlier studies and interventions in reminiscence emphasizing the opportunities of ICTs to easily show (old) pictures (gratification of being there), we found ICTs to be important for connecting with others (gratification of interaction) and easily finding materials to support memories (affordance of navigability). This finding is in line, however, with earlier research on the use of ICTs to enhance social and emotional wellbeing. Previous studies showed that older adults prefer to use general ICTs that support their daily life, rather than digital tools that were developed for one specific purpose (e.g. Blok et al., 2020).

\section{Strengths and limitations}

Our approach for collecting data can be considered a strength. First, we succeeded in including participants who initially denied that they recalled 
memories. Some were simply not aware that they recalled memories, while others even showed resistance; nevertheless, we convinced them to participate in the study, which shows a variety of participants in terms of reminiscence behaviour and preferences. Second, our stepped approach turned out to be relevant to answer our research question. Some older adults considered their participation an eye-opener regarding their own reminiscence behaviour. This reflects the fact that our approach allowed us to gather the information we would not have found with a single interview.

Although we took several measures to optimize the validity and reliability of our study, we noticed that some older adults found it complicated to reflect on their recalling of memories from a meta perspective. Although we asked participants to observe their regular reminiscence behaviour, some assumed they were supposed to recall memories on purpose as part of the study. Instead of reflecting on their process, these older adults rather focussed on the content of a memory. To optimize the input to the process, a longitudinal study could be considered next time. As we found that during the second interview participants were far more able to reflect on the process than during the first, another interview may help them even more to examine their own behaviour from a meta-perspective. Additionally, observational research such as observing gatherings of older adults could enrich and nuance our findings.

\section{Implications for practice}

Whereas most reminiscence interventions aim to provide sensory triggers such as (old) pictures or music, our findings show this is only one way to support reminiscence. First, we learned that sensory triggers are only one way to start a memory. Some older adults would rather be triggered by meaningful moments or the company of others. Second, whereas interventions often use old footage, we learned this may work for some older adults, but not all. Older adults who do not feel 'old' may be more motivated to engage in the process if the emphasis is on the present or on learning new things. Third, providing triggers only consider the first stage of the process. To successfully support older adults, we recommend taking into account all stages. For example, by bringing together the right people with whom to share memories - either in real life or virtually - or providing (digital) tools to help them reconstruct the stories triggered. Fourth, when connecting young and old by reminiscence, both should be considered equivalent as both groups can learn from one another. Finally, whereas most reminiscence interventions using ICTs focus on providing triggers to start memories (Lasar et al., 2014), our findings show that this is only one way of utilizing ICTs. Our research shows that many older adults have materials triggering memories themselves; suitable ICTs could help them organize these so that they can easily recall precious moments. Based on our findings, it seems furthermore relevant to use ICTs to connect older adults with others of any age to share memories. Our data show that dedicated tools for reminiscence are not even always necessary, as memories were often recalled using existing ICTs, such as WhatsApp, Facebook, or smartphone.

\section{Implications for further research}

Although our representation might suggest recalling memories always follows a fixed chronological order of consciously-taken steps, participants described several ways of unfolding the process. Future studies could investigate different routes through the process of reminiscence. Additional research could furthermore explore different types of 'recallers', allowing differentiation of interventions among different types of older adults. Previous studies showed how different types of persons recall memories for different reasons; our findings provide starting points for differentiation in the process (O'Rourke et al., 2016).

\section{Acknowledgements}

This work was conducted within the context of the projects MI-Tale and HiStory, supported by the Netherlands Organisation for Health Research and Development (ZonMw), within the European AAL program. We declare that none of the authors has any conflict of interest in the publication of this paper. We would like to thank Fleur Thomese for her support at the start of this study; Karin Kee for her support in coding, and Diane Shugart for checking the language.

\section{References}

Alqam, B.M. (2018). The effects of Reminiscence Therapy on Depressive Symptoms among Elderly: An Evidence Based Review. Trauma Acute Care Vol.3 No.1:1.

Blok, M., van Ingen, E., de Boer, A. H., \& Slootman, M. (2020). The use of information and communica-

tion technologies by older people with cognitive impairments: from barriers to benefits. Computers in Human Behavior, 104, [106173]. https://doi. org/10.1016/j.chb.2019.106173

Bohlmeijer, E., Roemer, M., Cuijpers, P. \& Smit, F. (2007). The effects of reminiscence on psychological well-being in older adults: A meta-analysis. Aging \& Mental Health, 11:3, 291-300. https://doi. org/10.1080/13607860600963547

Brankaert, R., Troenokarso, R., Wetten van, H., Lu, Y (2016). The Discover Dementia Pillow for reminiscence through music. Gerontechnology, 15(0), 120120. https://doi.org/10.4017/gt.2016.15.s.792.00

Butler, N. (1963) The Life Review: An Interpretation of Reminiscence in the Aged. Psychiatry, 26:1, 65-76. https://doi.org/10.1080/00332747.1963.11023339

Gibson, F. (2004). The past in the present: Using remi- 
niscence in health and social care. Health Professions Press.

Faraj \& Azad (2013). The Materiality of Technology: An affordance perspective. https://doi.org/10.1093/acp rof:oso/9780199664054.003.0012

Lazar, A., Thompson, H., \& Demiris, G. (2014). A systematic review of the use of technology for reminiscence therapy. Health education \& behavior: the official publication of the Society for Public Health Education, 41(1 Suppl), 51S-61S. https://doi. org/10.1177/1090198114537067

Mather M., Carstensen L.L. (2005). Aging and motivated cognition: the positivity effect in attention and memory. Trends Cogn. Sci. 9, 496-502. https://doi. org/10.1016/j.tics.2005.07.010

Parker R.G. (1995). Reminiscence: A Continuity Theory Framework, The Gerontologist, 35:4 515-525. https://doi.org/10.1093/geront/35.4.515

Ready R.E., Weinberger M.I., Jones K.M. (2007). How happy have you felt lately? Two diary studies of emotion recall in older and younger adults. Cogn. Emot. 21, 728-757. https://doi. org/10.1080/02699930600948269

O'Rourke N., Canham S., Wertman A., Chaudhury H., Carmel S, Bachner Y.G., Peres H. (2016). Holocaust Survivors' Memories of Past Trauma and the Functions of Reminiscence, The Gerontologist, 56:4 743-752. https://doi.org/vu-nl.idm.oclc. org/10.1093/geront/gnu168

Sun, W., Horsburgh, S., Quevedo, A., Liscano, R., Tabafunda, A., Akhter, R., Lemonde, M., Kapralos, B., Tokuhiro, A., Bartfay, E., Ashtarieh, B. (2020). Advancing reminiscence therapy through virtual reality application to promote social co-nectedness of persons with Dementia. Gerontechnology, 19(0), https://doi.org/10.4017/gt.2020.19.s.70041

Sundar, S.S. \& Limperos, A.M. (2013) Uses and Grats 2.0: New Gratifications for New Media. Journal of Broadcasting \& Electronic Media, 57:4, 504-525. https://doi.org/10.1080/08838151.2013.845827

Thomas L. \& Briggs P. (2016). Reminiscence through the Lens of Social Media. Frontiers in Psychology. 2016:7 DOI: 10.3389/fpsyg.2016.00870

Thornton S. \& Brotchie J. (1987). Reminiscence: A Critical Review of the Empirical Literature. British Journal of Clinical Psychology 26:93-111.

Webster, J. D. (1993). Construction and validation of the Reminiscence Functions Scale. Journals of Gerontology: Psychological Sciences, 48, 256-262. https://doi.org/10.1093/geronj/48.5.p256

Woods B., Portnoy S., Head D., \& Jones G. (1992). Reminiscence and life-review with persons with dementia: Which way forward? In G.M. Jones \& B.M.L. Miesen (Eds.), Care giving in dementia (137161). London: Routledge.

as a participant. I also ask for your permission to record this interview.

\section{APPENDIX I: INTERVIEW GUIDE \\ First visit}

Introduction and explanation of the project

Thank you for participating in this study. In this project we investigate in which ways people recall memories as they get older. These can be thoughts, conversations or feelings. It can be memories of a few years ago or events from an earlier phase of one's life. It can be about very personal things, but also about memories from World's history. We are interested in what is important to you.

Today I will explain the project further and ask you some introduction questions on the topic. We will also go through the diary together, in which we ask you to answer a number of questions in the coming weeks when you recall a memory.

In three weeks I will come back, to talk further with you about the memories you have included in the diary. Participating is anonymous, only I, the interviewer, know who you are. Of course you may share your stories with me, but you never have to if you do not feel comfortable. We are rather interested in the circumstances in which you recalled the memory. We do not ask you to hand in the diary afterwards, it mainly serves as a reminder and a tool for the next conversation.

Before we start, I ask you to sign the informed consent. By doing so, you indicate that I have informed you well and that you know your rights

\section{Background questions}

To start, I would like to ask you some background questions:

- Sex

- May I ask about your age?

- Your living situation?

- Family situation: do you have children, grandchildren?

- Important life events lately?

- Would you consider yourself someone frequently recalling memories'?

- How would you describe your experience with technology?

\section{Prompting the topic of memories}

Let's take the diary booklet and discuss an example together. Can you describe a moment when you recalled a memory lately?

Let's discuss the questions from the booklet together about this situation.

If participant does not come up with an example: Recalling memories serve several functions. Moreover, this does not always have to be conscious. I am curious if you recognize these ways an example based on the questions in the diary booklet (one or two examples are enough to support participant in the topic). of recalling memories and if you can describe 
- Do you ever recall memories, to spend time in an enjoyable way? (Boredom reduction)

- Does recalling memories ever help you to better understand yourself? (Identity forming)

- Do you ever recall memories as a nice conversation topic? (Conversation)

- Do you ever collect memories to process violent things from the past? (Bitterness Revival)

- Do you notice that you are getting more memories as you get older? (Death Preparation)

- Do you ever reminisce to solve current problems / see them in perspective? (Problem Solving)

- Do you ever reminisce about people who are no longer there? Who are they then? How do you do that? What does that do to you? (Intimacy Maintenance)

- Do you ever recall learning something about the past to the younger generations? (Teach / inform)

\section{Second visit}

Good to see you again. Today I am very interested in the examples you wrote down in your booklet. How did it go? Did you find it easy? Was it clear? What did describing the memories do to your feelings? Did you learn new things?

So let's start. Can you open the diary and describe the example you wrote down as first. Can you tell me more about it? What did you write down?

Follow-up: asking further questions on what participant shares.

Specific attention to the role of ICTs: When someone describes example of the use of an ICT, ask further questions on the why and how.

Thank you very much for participating!

\section{ApPendix II: Diary - ReCAlling memories}

A lot of people reminisce when they get older. This can be expressed in thoughts, conversations or sometimes just a feeling. It can be alone, or with others. It can be deliberate, spontaneous or

\section{My memories}

Figure 1. Diary cover. as a reaction to a stimulus.

From research we know that recalling memories can have different functions.

- It can help to process painful experiences from the past.

- It can be a fun way to spend time, an activity for leisure;

- Memories can be a good conversation topic in conversations with others. Recalling memories together can produce beautiful conversations and even promote a sense of connection.

- Some people retrieve memories in order to prepare for the end. It helps them to complete their lives.

- Recalling memories can help you to understand yourself better. For example, to understand how experiences have shaped you into who you are now.

- Recalling memories of loved ones who are no longer there can contribute to a sense of intimacy and connectedness.

- Past experiences can help to solve problems you encounter in the present.

- Recalling memories can be an important way to pass on history and personal experiences to the next generation.

We already know a lot about why people reminisce, but not so much about what they do when recalling memories. That is why we ask you to collect some examples in this booklet. It is not a diary in which we ask you to report daily, but a tool to become aware of how you recall memories. The questions in the booklet will hopefully help you on your way. In a few weeks I will be happy to talk to you about how you have thought about the past.

Which day is it today? (please mark) Sunday /Monday /Tuesday /Wednesday /Thursday /Friday /Saturday

What was your memory about? (keywords are sufficient)

What period of time was your memory about? (please mark)

Some years ago / an earlier stage of my life

Were other people present when you recalled the memory (please mark)

No, I was alone / Yes, namely:

If you recalled memories together with others: who started this process?

Did you recall the memory on purpose? (please mark)

Yes, I consciously spent some time on it / No, it just happened / No, I was triggered, namely by.. 


\section{The process of reminiscence among older adults}

Were there any tools supporting the memory? (e.g. pictures / video / objects)? foto's/video/ voorwerpen/..)? If yes: Did you use these on purpose?

Recalling the memory gave me a Positive / Negative / Neutral feeling (please mark) 